Dermatology 2009;218:69-70

DOI: $\underline{10.1159 / 000161122}$

\section{Anti-CTLA4 Monoclonal Antibody Induced Sarcoidosis in a Metastatic Melanoma Patient}

\section{A. Eckert, A. Schoeffler, S. Dalle, A. Phan, L. Kiakouama, L. Thomas}

Service de Dermatologie, Hôpital de l'Hôtel-Dieu, Lyon, France

\section{Key Words}

Anti-CTLA4 monoclonal antibody • Ipilimumab •

Melanoma $\cdot$ Sarcoidosis

A 67-year-old woman was diagnosed as having $1.5-\mathrm{mm}$ superficial spreading melanoma on the back in 2002. She had no medical history. The axillary sentinel lymph node was positive. The patient relapsed in October 2004 with histopathology-proven supraclavicular metastatic nodes. After incomplete surgery, she received radiotherapy and combined cytostatic chemotherapy from December 2004 to February 2005. Recurrent metastasis in a spinal lymph node was again treated by surgery in May 2005 while cytostatic therapy was suspended. The patient then relapsed in December 2005, in January 2006 and in March 2006 with subcutaneous nodules on the chest, neck and axillae. All lesions were surgically removed. In March 2006, cytology-proven liver metastases appeared and were subsequently treated by radiofrequency ablation. Recurrent liver metastatic disease led us, in September 2006, to propose her an inclusion in a phase II clinical trial with ipilimumab, an anti-CTLA4 monoclonal antibody (CA184022).

The patient was treated every 3 weeks by intravenous infusion of anti-CTLA4 monoclonal antibody at a dose unknown to the observer of either $0.3,3$ or $10 \mathrm{mg} / \mathrm{kg}$ for 12 weeks. At the end of the induction phase (after 4 infusions), in December 2006, because of the progression of liver metastases, the patient was then withdrawn from the first trial and included in a new clinical trial (CA184025) with intravenous $10 \mathrm{mg} / \mathrm{kg}$ ipilimumab every 3 weeks. In April 2007, at the end of the reinduction phase, a new evaluation was done. The CT scan showed a stabilization of the liver metastases and the onset of new mediastinal lesions. One month later, the mediastinal masses were found increased in size, and pulmonary parenchymatous micronodular lesions appeared. The treatment was then discontinued with the diagnosis of metastatic disease progression. The patient related recent occurrence of low-grade dyspnea, and a new skin lesion was observed on her face while hepatic lesions remained perfectly stable. The facial lesion was then biopsied, and pathology revealed a noncaseating granuloma consistent with sarcoidosis. Bronchial biopsy was also performed and disclosed sarcoidosis lesions. The angiotensinconverting enzyme level was elevated (103 IU/1, normal below 67). The bronchoalveolar lavage showed a moderate lymphocyte count (5\%) with a predominance of CD4; however, the CD103/CD4 ratio was 0.97 . Counts of the regulatory CD $4+\mathrm{CD} 25+$ cells in the peripheral blood as well as in the bronchoalveolar lavage were normal. The phenotype of circulating lymphocytes was normal. We reestablished the diagnosis as sarcoidosis associated with stable metastatic disease. A CT scan performed 3 months after discontinuation of the anti-CTLA4 therapy revealed a decrease in size of the mediastinal masses.

The cytotoxic-T-lymphocyte-associated antigen CTLA4 is expressed on the surface of most $\mathrm{T}$ cells only after activation. Its binding to B7 family receptors on antigen-presenting cells antagonizes T-cell activation, inhibits IL-2 production and receptor expression and interferes with cell-cycle regulation. CTLA4 downregulates T-cell responses and is involved in the immune tolerance of self-antigens. It is thought that use of anti-CTLA4 antibody could enhance the response of tumor-reactive $\mathrm{T}$ cells against tumor 'self'-antigens. In animal models, anti-CTLA4 enhanced antitumor immunity. Anti-CTLA4 antibodies have been used in human melanoma, and preliminary results showed cases of regression of this cancer. This therapeutic agent has autoimmune adverse effects (dermatitis, hepatitis, hypophysitis, diarrhea and colitis). Response appears to be significantly associated with the onset of autoimmune reactions. However, the use of corticosteroids to treat severe induced autoimmune manifestations does not seem to affect the antitumor effect $[1,2]$.

Sarcoidosis is a multisystem granulomatous disorder of unclear etiology. It is thought that exaggerated cellular immunity could play a key role through a Th1 T-cell-mediated response to an unknown antigen. IL-2 synthesis and the expression of IL-2 receptors is found increased, and it is thought that the activation of CD4+ T cells is associated with $\gamma$-interferon production and macrophage activation that lead to the granuloma formation [3].

This is the first report of pulmonary and cutaneous sarcoidosis induced by an anti-CTLA4 antibody in the treatment of a metastatic melanoma. We can hypothesize that anti-CTLA4 antibody made possible the enhanced T-cell response implicated in the constitution of the granuloma.

The etiological diagnosis of mediastinal lymphadenopathies in metastatic melanoma cases can be very difficult; a differential diagnosis with sarcoidosis is indeed extremely difficult to estab-

\section{KARGER}

(c) 2008 S. Karger AG, Basel

Fax +41613061234

E-Mail karger@karger.ch

www.karger.com
Accessible online at: www.karger.com/drm 
lish, and an excessive diagnosis of melanoma metastatic spread can be easily made. Moreover, the association of sarcoidosis and metastatic cancer (including melanoma) is not uncommon. In our case, the biopsy of a cutaneous lesion led us to consider the correct diagnosis that was confirmed by bronchial biopsies, elevated angiotensin-converting enzyme level and regressive evolution.

Because of the pathogeny of sarcoidosis and of the biological effect of ipilimumab, we believe that such a side effect could become not so uncommon if wider use of this drug happens. The differential diagnosis with melanoma metastatic spread should be made very cautiously since it may lead to inappropriate therapeutic choices.

\section{References}

1 Maker AV, Phan GQ, Attia P, Yang JC, Sherry RM, Topalian SL, Kammula US, Royal RE, Haworth LR, Levy C, Kleiner D, Mavroukakis SA, Yellin M, Rosenberg SA: Tumor regression and autoimmunity in patients treated with cytotoxic T lymphocyte-associated antigen 4 blockade and interleukin 2: a phase I/II study. Ann Surg Oncol 2005;12: 1005-1016.

2 Weber JS: The clinical utility of cytotoxic T lymphocyte antigen 4 abrogation by human antibodies. Melanoma Res 2006;16:379-383.

3 Baughman RP, Lower EE, Du Bois RM: Sarcoidosis. Lancet 2003;361: 1111-1118.

Luc Thomas

Service de Dermatologie, Hôpital de l'Hôtel-Dieu

1, place de l'Hôpital

FR-69288 Lyon Cedex 02 (France)

Tel. +33 4724030 00, Fax +33472413132

E-Mail luc.thomas@chu-lyon.fr 